Jorge Puma, Los maoístas del norte de México: breve historia de Política Popular-Línea Proletaria, 1969-1979 / Maoists of Northern Mexico: A Short History of Política Popular-Línea Proletaria, 1969-1979, Revista Izquierdas, 27, abril 2016, ISSN 0718-5049, pp. 200-229

\title{
Los maoístas del norte de México: breve historia de Política Popular-Línea Proletaria, 1969-1979*
}

\section{Maoists of Northern Mexico: A Short History of Política Popular-Línea Proletaria, 1969-1979}

\author{
Jorge Iván Puma Crespo**
}

\footnotetext{
* Artículo basado en mi tesis de Maestría en Historia Internacional y Comparada Populismo Maoísta: Un sendero que no condujo a la lucha armada. 1969-1979 del Centro de Investigación y Docencia Económicas (CIDE).

** Mexicano, historiador y licenciado en Ciencia Política por el CIDE, jpuma4@gmail.com
} 


\section{Resumen:}

Se analiza la evolución de Política Popular, un grupo maoísta activo entre 1968 y 1979 , en el marco de la construcción de una alternativa a la organización partidaria y la vía armada. La investigación se sustenta en testimonios de ex militantes y documentos internos de la organización, así como una amplia revisión de la literatura disponible, en especial, estudios de historia regional. El texto concluye que las condiciones del entorno político y el énfasis en la línea de masas llevaron a Política Popular al activismo social y sindical.

Palabras Clave: Maoísmo, historia oral, historia regional, línea de masas, norte de México, sindicatos.

Recibido: 4 agosto 2015

Aceptado: 5 diciembre 2015

\begin{abstract}
:
This essay studies evolution of Política Popular, a Maoist group operating from 1968 to 1979 . It presents its history in the context of the development of an alternative to armed struggle and party politics. The research is grounded in the testimonies of former militants, internal documents of the organization and a comprehensive literature review with a focus in regional history studies. Delving into Política Popular's history we find that political context and the group fixation with mass line resulted in union and social activism.
\end{abstract}

Keywords: Maoism, Oral History, Regional History, Mass line, Northern Mexico, Unions.

\section{Introducción}

La historiografía sobre la izquierda en México en el siglo XX suele ir de la mano del estudio de la evolución del Partido Comunista Mexicano (PCM) y sus disidencias. A veces, la narrativa culmina en el abandono de la tradición socialista en 1989 con la fundación del Partido de la Revolución Democrática (PRD) y su amalgama entre la tradición comunista y el nacionalismo revolucionario. El estallido de la rebelión en Chiapas en 1994 y las protestas estudiantiles de finales de siglo no modifican en lo esencial ese discurso, a lo mucho se oscila entre una valoración positiva del camino a una socialdemocracia "a la mexicana" y una fábula precautoria del abandono de los principios. Sólo la historiografía del movimiento armado socialista de los años setenta cuestiona el paradigma imperante, pero lo hace relegando otras vías y actores. Después de 1968 la llamada "izquierda social" se convirtió en el referente más cercano de la izquierda para miles de mexicanos en el campo y la ciudad; hoy, no obstante, es la gran perdedora en la lucha por la memoria histórica.

Ahora bien, la atracción por el modelo no burocrático de socialismo desarrollado durante la Revolución Cultural en China llevó a centenares de jóvenes universitarios a formar partidos y grupos con etiquetas de Marxista-Leninista en lugares tan diversos como 
la India, Perú o Francia. México no fue la excepción. Varios factores explican por qué los grupos y experiencias del maoísmo local han sido hasta hace poco relegados literalmente a notas marginales de la historia de la izquierda en México. En otro trabajo exploré las razones de este olvido: escasez de fuentes escritas, sesgo ideológico de la historiografía mexicana sobre el tema, la cercanía con el régimen de varios de los ex militantes maoístas, etc. ${ }^{1}$ El propósito de esta investigación es llenar ese vacío y en este ensayo ofrezco un ejemplo de una vía revolucionaria que, sin sucumbir a la tentación de las armas, emprendió una ruta distinta de organizar a colonos, obreros y campesinos en el norte de México: Política Popular. ${ }^{2}$

Existen antecedentes del movimiento maoísta en México desde inicios de los años sesenta. En esa ocasión, como en otros partidos comunistas latinoamericanos, algunos militantes del PCM, encabezados por Camilo Chávez y Edelmiro Maldonado, tomaron la bandera de la postura china frente a la dirigencia pro soviética del partido. ${ }^{3}$ Sin embargo, estos grupos minoritarios no lograron generar un proyecto político que sobreviviera los vaivenes de la represión estatal y la lucha interna dentro de la izquierda mexicana.

Cabe mencionar que existieron otros grupos de línea de masas durante la década de 1970 que mantuvieron en diversos momentos relaciones de rivalidad y alianza con Política Popular, al grado que en la siguiente década tendieron a aglutinarse con un sector de ésta en las coordinadoras de masas. ${ }^{4}$ En ese sentido la historia del maoísmo en México, sin tomar en cuenta la vertiente guerrillera, trasciende la experiencia de Política Popular.

\section{1. "Hacia una política popular" como respuesta al desafío de "ir al pueblo"}

A diferencia de otros grupos maoístas, Política Popular alcanzó una implantación mayor y las ramificaciones de su actuar político dentro de la izquierda mexicana fueron más allá de su esfera de influencia directa. Su modelo de acción política marcó el ritmo de la conformación de una "izquierda social" preocupada por la gestión económica y la movilización popular fuera del marco de la vanguardia revolucionaria y la actividad partidaria. De tal forma que es posible hablar del "momento maoísta" de la izquierda social mexicana, el cual abarcó un período de veinte años entre 1968 y 1988. Este periodo

\footnotetext{
${ }^{1}$ Véase Jorge Ivan Puma Crespo, Populismo Maoísta: Un sendero que no condujo a la lucha armada. 19681979, México, D.F., Centro de Investigación y Docencia Económicas, 2014.

${ }^{2}$ En este trabajo utilizaré por economía el término Política Popular para referirme tanto al grupo original como a las organizaciones que derivaron de él (Comité de Defensa Popular-Durango, Frente Popular Tierra y Libertad, Línea de Masas, Línea Proletaria....)

3 Véase Luis Hernández Navarro, "Camilo Chávez, el metalúrgico rojo," en La Jornada, México, D.F., 4 de enero 2011.

${ }^{4}$ Para la historia de las coordinadoras de masas puede consultarse Josiane Bouchier, "La paradoja de la unidad. El movimiento urbano popular y la Coordinadora Nacional del Movimiento Urbano Popular (CONAMUP)," en Movimientos sociales en México durante la década de los 80, ed. Sergio Zermeño yJesús Aurelio Cuevas Díaz, México, D.F., UNAM, 1990.
} 
comprende toda la existencia de Política Popular-Línea Proletaria, se extiende hasta la formación de las grandes coordinadoras de masas e intentos de reagrupamiento de la familia maoísta, y termina con la explosión neo-cardenista de 1988.

Política Popular surgió en 1968 al calor del movimiento estudiantil como una iniciativa liderada por Adolfo Orive Bellinger en la escuela de economía de la Universidad Nacional Autónoma de México (UNAM). Su principal postulado era que los activistas del movimiento estudiantil debían integrarse a las masas. Según la estrategia delineada en el documento fundacional del grupo, el folleto "Hacia una Política Popular", se trataba de salir de los cauces institucionales y hacer política "popular". Es decir, buscaban generar formas organizativas independientes con elementos de democracia directa (asambleas) y apelar a la movilización de los colonos, campesinos y estudiantes como medio de solución de los problemas económicos. ${ }^{5}$ La idea central era que los activistas se fusionaran con el "pueblo" y de esta convivencia se politizara a la población para que el pueblo mismo resolviera sus necesidades.

Si bien la iniciativa de formar Política Popular comienza en la UNAM, pronto se integró a ella un grupo de brigadistas del Comité de Lucha de la Escuela Superior de Ingeniería Mecánica y Eléctrica (ESIME) del Instituto Politécnico Nacional. El vínculo con los politécnicos lo establecieron Alberto Anaya y Jorge Alfonso Calderón, en ese entonces estudiantes de economía en la UNAM, quienes impartieron un curso de marxismo en un círculo de estudios formado por los brigadistas del ESIME con la finalidad de estudiar la situación política nacional. ${ }^{6}$ Esa relación tuvo como consecuencia la integración de varios estudiantes al naciente grupo, por el que realizaron labores de propaganda en las instalaciones de Zacatenco y Allende y pugnaron por el control del Comité de Lucha en competencia con militantes del PCM y otros grupos maoístas. ${ }^{7}$ Esa experiencia, junto con los tempranos intentos de hacer trabajo en las colonias populares de la ciudad de México y las zonas rurales de su periferia, tenían los militantes politécnicos que permanecieron en la organización cuando posteriormente se trasladaron a las colonias populares de Durango y Monterrey.

Aunque hubo ciertas incursiones en las zonas fabriles de la ciudad de México durante el movimiento de 1968, el primer intento de llevar a la práctica los postulados del "Hacia una Política Popular" fue una expedición en 1969 a Tecomaxtlahuaca, una localidad

\footnotetext{
${ }^{5}$ Véase [Adolfo Orive Bellinger], Hacia una política popular, Durango, Editorial Universidad Juárez del Estado de Durango, 2006.

${ }^{6}$ Mario Ortega Olivares, Octubre Dos. Historias del movimiento estudiantil, México, D.F., Editorial Sierpe, 2013, 276. y Alberto Escudero (militante de Política Popular en Durango), entrevistado por Jorge Puma, Durango de Victoria, 26 de junio de 2013.

${ }^{7}$ Ortega Olivares, op. cit., 342-345.
} 
Jorge Puma, Los maoístas del norte de México: breve historia de Política Popular-Línea Proletaria, 1969-1979 / Maoists of Northern Mexico: A Short History of Política Popular-Línea Proletaria, 1969-1979, Revista Izquierdas, 27, abril 2016, ISSN 0718-5049, pp. 200-229

de la mixteca oaxaqueña (verde) colindante con el estado de Guerrero. ${ }^{8}$ El balance de esos primeros intentos de integración varía entre los protagonistas, pues mientras Javier Gil, uno de los primeros brigadistas, recalca la experiencia ganada; Orive lo considera un paso en falso. En opinión de Adolfo Orive dicho intento no prosperó ante la negativa de los campesinos de realizar la "revolución social" en los términos planteados por los maoístas. En palabras de Orive, "[...] nos dimos cuenta que no, que la pobreza no necesariamente determinaba el deseo de la gente de cambio, y querían cambiar para nada más mejorar sus condiciones, no un cambio como nosotros planteábamos". 9

Sin embargo, este comienzo funcionó como base de futuras incursiones. Luego de reunirse en Tacámbaro, Michoacán en 1969, decidieron ir a zonas rurales del norte (Nayarit, Durango, y Sonora [amarillo]) para después extenderse a otras regiones (San Luis Potosí, Coahuila, Chihuahua, Zacatecas, Hidalgo, Michoacán [Lázaro Cárdenas], Querétaro, Chiapas, Sonora y Guerrero [rojo]). Fue esta segunda oleada la que sentó los cimientos para la extensión de su modelo organizativo y su posterior auge en las coordinadoras populares de finales de los años setenta y principios de los años ochenta. El siguiente mapa muestra el proceso de expansión de Política Popular del que trata este artículo.

\footnotetext{
${ }^{8}$ Javier Gil (militante fundador de Política Popular), entrevistado por Jorge Puma, México, D.F., 30 de septiembre de 2013. y Hugo Andrés Araujo de la Torre (militante fundador de Política Popular), entrevistado por Jorge Puma, México, D.F., 30 de julio de 2014.

${ }^{9}$ Adolfo Orive Bellinger (líder de Política Popular), entrevistado por Jorge Puma, México, D.F., 10 de agosto de 2012.
} 
Jorge Puma, Los maoístas del norte de México: breve historia de Política Popular-Línea Proletaria, 1969-1979 / Maoists of Northern Mexico: A Short History of Política Popular-Línea Proletaria, 1969-1979, Revista Izquierdas, 27, abril 2016, ISSN 0718-5049, pp. 200-229

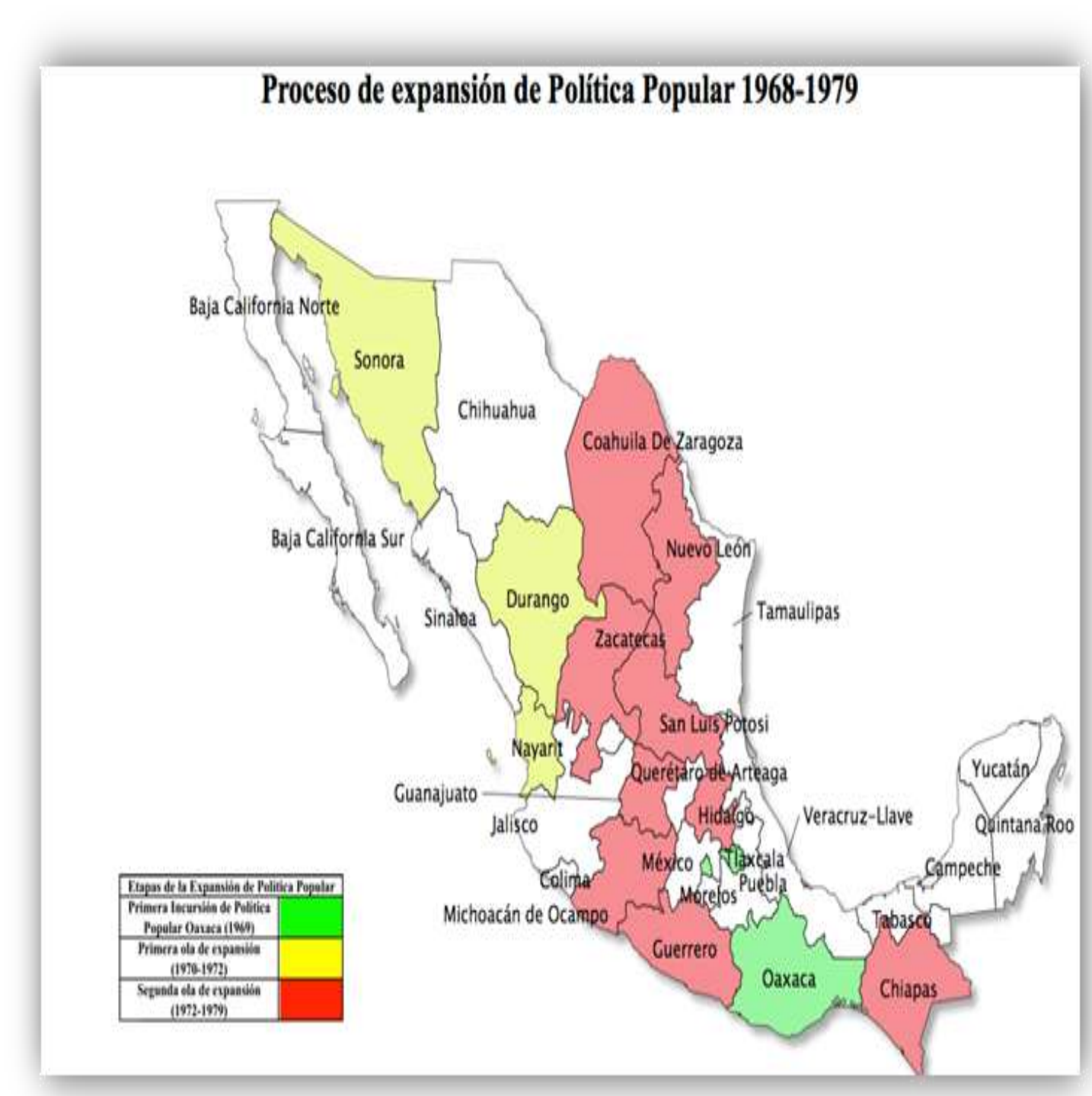

Mapa elaborado con información obtenida por el autor en sus entrevistas.

\section{Durango y Monterrey. Éxitos y fracasos de la larga marcha al campo}

Los casos de Durango y Monterrey son emblemáticos de la transformación que experimentó Política Popular en el norte del país a mediados de la década de los setenta. Tras un intento de continuar con el guión maoísta y después del fracaso de la integración con el campesinado del norte del estado de Durango en 1971, un grupo de brigadistas se trasladó a la capital de dicho estado. No era la primera vez que buscaban realizar un trabajo 
Jorge Puma, Los maoístas del norte de México: breve historia de Política Popular-Línea Proletaria, 1969-1979 / Maoists of Northern Mexico: A Short History of Política Popular-Línea Proletaria, 1969-1979, Revista Izquierdas, 27, abril 2016, ISSN 0718-5049, pp. 200-229

de organización popular en la ciudad de Durango. Una primera brigada, en la que participaron Alberto Anaya y Alberto "El Güero" Escudero, había llegado antes con la estela del movimiento estudiantil duranguense de 1970, presuntamente de la mano de Carlos Ornelas, uno de los líderes de ese movimiento. ${ }^{10}$ La incursión no prosperó por lo que Alberto Anaya partió a Monterrey mientras que "El Güero" salió rumbo a Chihuahua para cooperar con quienes fundarían el Comité de Defensa Popular de Chihuahua. Al desaparecer ambos del panorama duranguense, Jesús Vargas fue quien retomó el trabajo en la entidad a principios de 1972. Esta vez la brigada conformada por Jesús Vargas, su esposa Marcela Frías, Marcos Cruz, Ramón Durán y "El Güero" Escudero (quien regresó convencido por Jesús Vargas), comenzó a organizar a los colonos empobrecidos de las afueras de la ciudad. En ese proceso forjaron una base popular y se independizaron de la dirección de Orive. Al paso del tiempo esto adquiriría un tinte de conflicto ideológico y desataría la lucha por el control de la organización.

En 1972, luego del fracaso en la creación de una base de adherentes entre las organizaciones campesinas, los brigadistas empezaron a organizar a los arrendatarios de cuartos de vecindad de la ciudad de Durango para exigir una reducción en el pago del servicio de agua. En marzo de ese año las autoridades subieron la cuota por consumo de 6.25 a 50 pesos mensuales con lo que brindaron el pretexto ideal para la movilización de una coalición de obreros, colonos y campesinos. La molestia por la medida fue tan grande que el 10 de agosto de 1972 una manifestación de 900 personas forzó al jefe de la Junta Federal de Agua Potable a atenderlos. Quince días después, ante la insuficiencia de la respuesta de las autoridades, se realizó una nueva manifestación con el doble de asistentes. La lucha por el agua se recrudeció e incluyó la toma de las oficinas de la Junta Federal de Agua Potable. ${ }^{11}$ Para Septiembre de 1972, la recién formada Unión Popular Independiente logró la cancelación del aumento a través de un acuerdo firmado, entre otros, por el futuro gobernador Maximiliano Silverio Esparza. El triunfo del movimiento por el agua demostró a los brigadistas que su estrategia de confrontación y negociación podía funcionar.

Esta estrategia evolucionó a la invasión de terrenos para fundar nuevas colonias controladas por militantes de Política Popular. El 9 de febrero y el 8 de marzo de 1973 inquilinos de las vecindades de Durango intentaron posesionarse de terrenos que eran propiedad del gobierno estatal. Sin embargo, la violenta reacción de la policía estatal los forzó a retirarse e incluso algunos de los brigadistas fueron encarcelados. ${ }^{12}$ La espiral represiva del gobierno estatal desembocó en el secuestro de los brigadistas por agentes judiciales en abril y su consecuente expulsión de Durango, así como la detención de Jesús Vargas y Marcela Frías en el campo militar número 1 de la ciudad de México por dos

\footnotetext{
${ }^{10}$ Gabino Martínez Guzmán, CDP. El Poder del Pueblo, Durango, México, Universidad Juarez del Estado de Durango, 2012, 48-49.

11 "El movimiento del agua. El sector más pobre de Durango, organiza la lucha popular en torno al problema del agua.," en Punto Crítico, México, D.F., Diciembre 1972, 26.

${ }^{12}$ Unión Popular Independiente, "Carta de 2000 familias de Durango," en Punto Crítico, Marzo 1973, 44.
} 
Jorge Puma, Los maoístas del norte de México: breve historia de Política Popular-Línea Proletaria, 1969-1979 / Maoists of Northern Mexico: A Short History of Política Popular-Línea Proletaria, 1969-1979, Revista Izquierdas, 27, abril 2016, ISSN 0718-5049, pp. 200-229

meses. La campaña para lograr su liberación involucró manifestaciones en Durango y Chihuahua, así como desplegados en periódicos de la capital y una carta de José Revueltas pidiendo su libertad. ${ }^{13}$ El grado de solidaridad de la izquierda estudiantil de la ciudad de México con la lucha de los colonos en Durango y la demanda por la libertad de los detenidos se refleja en el siguiente desplegado publicado en Excélsior en mayo de 1973:

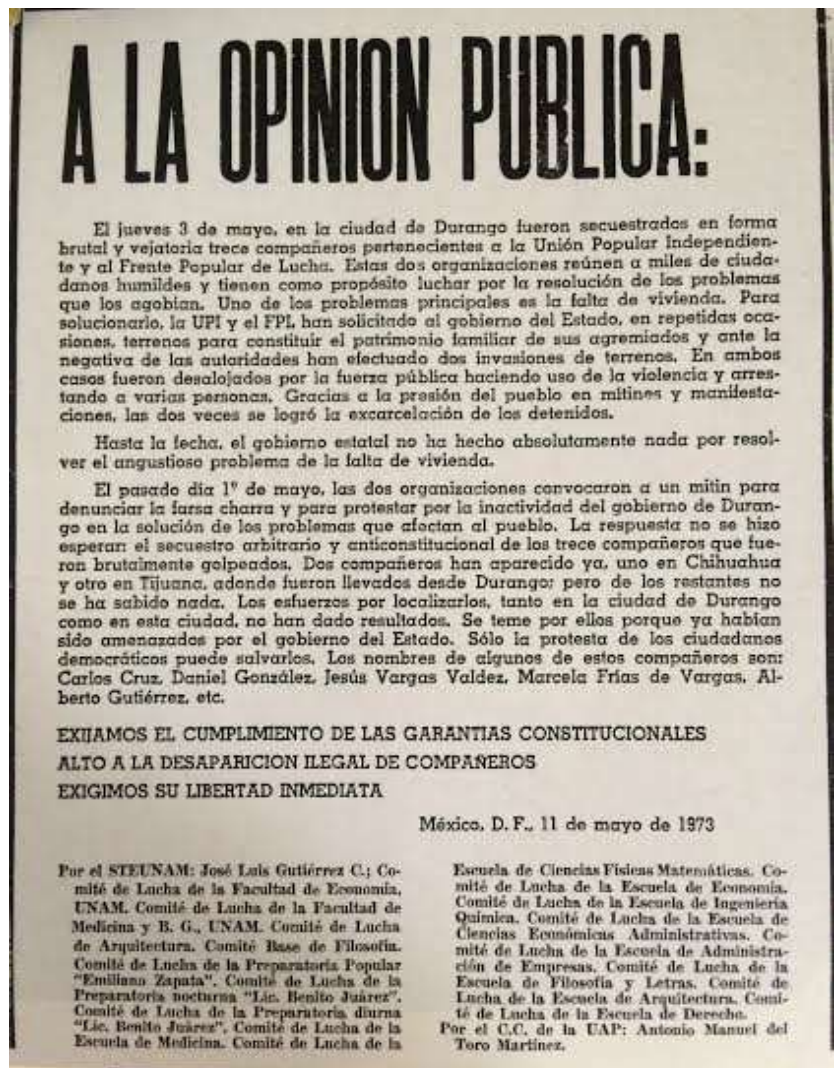

Foto del autor tomada del desplegado "A la Opinión Pública”, Excélsior, 12 de mayo 1973.

De este trance los brigadistas salieron fortalecidos y en septiembre de 1973, después de negociar con "el Instituto Nacional de Desarrollo de la Comunidad (INDECO), obtuvieron un acuerdo por el cual recibirían 20 hectáreas a pagar en cinco años. En esas

\footnotetext{
13 Jesús Vargas Valdés y Marcela Frías (Militantes de Política Popular en Durango), entrevistados por Jorge Puma, Chihuahua, 13 de agosto de 2013.
} 
Jorge Puma, Los maoístas del norte de México: breve historia de Política Popular-Línea Proletaria, 1969-1979 / Maoists of Northern Mexico: A Short History of Política Popular-Línea Proletaria, 1969-1979, Revista Izquierdas, 27, abril 2016, ISSN 0718-5049, pp. 200-229

tierras crearon la primera "colonia popular" de Durango, División del Norte". ${ }^{14}$ Movilizar masas para invadir predios y después negociar con el gobierno se convirtió en la marca distintiva de Política Popular en Durango.

La colonia División del Norte en Durango, en el periodo entre 1973 y 1976, funcionó como un territorio liberado y autogestivo donde incluso los elementos del lumpen proletariado urbano participaron en mecanismos de autogobierno de la colonia. Los brigadistas y colonos trabajaron por dotar de servicios educativos y de salud a sus habitantes sin la participación del gobierno. En jornadas de trabajo colectivo construyeron una escuela primaria y echaron a andar un jardín de niños donde los hijos de los colonos recibieron alimentación y cuidado mientras sus padres trabajaban. En esos años los brigadistas dividían su tiempo entre el trabajo político de la organización y las labores en la tortillería y el taller de carpintería de la colonia. ${ }^{15}$ En concordancia con su ideología política los colonos y brigadistas construían con sus actos el germen de la nueva sociedad.

Hasta 1976 la organización se extendió lentamente por Durango y solamente fundaron dos nuevas colonias, la Emiliano Zapata y la Lucio Cabañas. Por su parte, Ramón Durán se trasladó de la ciudad al campo para propagar la influencia de Política Popular a la zona de los llanos de Victoria. En este último caso, los brigadistas de Política Popular conjugaron sus esfuerzos con los de un naciente movimiento campesino para conformar la organización César Guillermo Méraz, en una extraña experiencia de entrismo de la Confederación Nacional Campesina, central campesina controlada por el Partido Revolucionario Institucional (PRI). La organización generó grandes expectativas entre los brigadistas por la fuerza que alcanzó al lograr en 1978 la recuperación de una póliza asegurada ante la pérdida de la cosecha de frijol el año anterior. Por ello, la organización sobreviviría el ocaso de Política Popular a finales de los años setenta, aunque duramente golpeada por los errores organizativos generados por la rotación de cuadros y por la paulatina desmovilización de los campesinos. ${ }^{16}$ Con el tiempo, el movimiento popular y campesino de Durango habrían de encontrar una salida en la vía electoral representadas por

\footnotetext{
${ }^{14}$ Paul Lawrance Haber, "¡Vamos por la dignidad de Durango! Un estudio del poder sociopolítico," en Movimientos sociales e identidades colectivas. México en la década de los noventas, México, D.F., La Jornada Ediciones-Centro de Investigaciones Interdisciplinarias en Ciencias y Humanidades/UNAM, 1997, 57.

${ }^{15}$ Jesús Vargas Valdés y Marcela Frías (Militantes de Política Popular en Durango), entrevistados por Jorge Puma, Chihuahua, 13 de agosto de 2013.

${ }^{16}$ Véase Arturo León López, El movimiento campesino en los Llanos de Victoria, Durango, 1970-1980, México, D.F., UAM Xochimilco, 1986. y los artículos de Ramón Durán, "Veinte Años de Lucha de Masas Parte XIII: El triunfo del movimiento de masas es a la vez el inicio de una futura división al interior de la dirección," en El Sol de Durango, 18 de marzo de 1991.; "Veinte Años de Lucha de Masas Parte XIV," en El Sol de Durango, 22 de marzo de 1991; "Veinte Años de Lucha de Masas Parte XV," en El Sol de Durango, 25 de marzo de 1991; "Veinte Años de Lucha de Masas Parte XVI," en El Sol de Durango, 29 de marzo de 1991; "Veinte Años de Lucha de Masas Parte XVII," en El Sol de Durango, 01 de abril de 1991.; y "Veinte Años de Lucha de Masas Parte XXI," en El Sol de Durango, 22 de abril de 1991.
} 
el partido del Comité de Defensa Popular y en el Partido del Trabajo, pero para entonces el horizonte de democracia directa y Política Popular sólo serían el pasado de una ilusión.

Más al norte, Alberto Anaya, todavía con apoyo de Orive, consiguió en 1971 reclutar a brigadistas estudiantiles que desde 1967 trabajaban con colonos marginados de las afueras de Monterrey. Algunos de estos brigadistas, como Agustín Acosta (a) "Tilín”, ya habían tenido contacto con el maoísmo a través de una de las escisiones de la Liga Comunista Espartaco, así que su integración dentro de Política Popular no fue tan complicada. Además, al núcleo de brigadistas locales de origen estudiantil pronto se agregaron varios militantes de Política Popular provenientes de la región lagunera. ${ }^{17}$

En Monterrey el avance del movimiento urbano popular no fue un fenómeno espontáneo. En realidad, le precedieron varios intentos de miembros del PCM por organizar a los habitantes de la periferia de la ciudad. Las asociaciones sobrevivientes de ese proceso fue lo que encontraron los militantes del movimiento estudiantil radicalizados en las luchas por la autonomía de la Universidad de Nuevo León. En sus memorias inéditas Agustín Acosta menciona a la Central Independiente de Organizaciones del Pueblo dirigida por militantes del PCM como un antecedente directo de la lucha por organizar a los colonos de manera independiente del PRI. En su opinión resulta necesario "dar un rotundo mentís a quienes soberbiamente creen que en los años 70 descubrieron el hilo negro en lo concerniente a la organización de los posesionarios[...]" ${ }^{\text {18 }}$ Otro elemento que contribuyó a fortalecer el proceso organizativo de "posesionarios" fue el resurgimiento de la militancia obrera, en particular, el de la disidencia sindical ferrocarrilera encabezada por Demetrio Vallejo. ${ }^{19}$ Todas estas condiciones le dieron a los jóvenes brigadistas un menú de experiencias organizativas de donde abrevar y aliados con los que enfrentar los embates del gobierno y oligarquía locales.

El momento cumbre del trabajo conjunto de los brigadistas locales y los recién llegados fue la fundación de la colonia Tierra y Libertad. ${ }^{20}$ Ésta y otras colonias populares se desarrollaron, en su primera etapa, como un foco de organización popular radicalizada. En un principio, se trató de "zonas liberadas" de la influencia de los sectores corporativos del PRI y con elementos de una cultura política igualitaria. Diana Villarreal y Víctor Castañeda en un estudio sobre la urbanización en Monterrey explican de la siguiente manera como operó el modelo impulsado por los maoístas en Tierra y Libertad:

\footnotetext{
${ }^{17}$ Agustín Acosta Zavala (militante de Política Popular en Monterrey, Nuevo León), entrevistado por Jorge Puma, México, D.F., 22 de noviembre de 2013.

${ }^{18}$ Agustín Acosta Zavala, Así lo recuerdo, Torreón, Coahuila, 2015, 38.

${ }^{19}$ Ibid., 104-109.

${ }^{20}$ Agustín Acosta Zavala (militante de Política Popular en Monterrey, Nuevo León), entrevistado por Jorge Puma, México, D.F., 22 de noviembre de 2013.
} 
Jorge Puma, Los maoístas del norte de México: breve historia de Política Popular-Línea Proletaria, 1969-1979 / Maoists of Northern Mexico: A Short History of Política Popular-Línea Proletaria, 1969-1979, Revista Izquierdas, 27, abril 2016, ISSN 0718-5049, pp. 200-229

Este tipo de gestión nace con un amplio apoyo de la base de colonos y se constituye como organización en torno a las demandas de tierra y vivienda. El mecanismo de acceso a la tierra se llevó a cabo mediante la ocupación masiva pero organizada de predios baldíos, acción que precedía a la lotificación y construcción de la vivienda, esto es, la formación de un nuevo poblamiento. La concepción de este último trasciende las demandas estrictamente de carácter urbano: estas se contemplan dentro de un plan integral de obras que comprende la gestión de los servicios -por lo general tomados directamente de las redes públicas ante la negativa de las autoridades a instalarlos-, la gestión y la construcción de un equipamiento colectivo básico (escuelas, centros de salud) y la incorporación de los colonos en la esfera productiva dentro de un mismo poblamiento. ${ }^{21}$

Estos mismos autores señalan que la ocupación de terrenos en la zona central de Monterrey en un área colindante a predios con un alto valor provocó la fuerte animadversión de sectores gubernamentales y privados interesados en el desarrollo inmobiliario. En ese contexto, se entiende que años después Alfonso Domínguez Martínez, gobernador priista de Nuevo León, con una combinación de fuertes medidas represivas y un programa de regularización de la propiedad, logró desactivar ese espacio de descontento popular. Para 1982, a la mitad de su sexenio, a través del programa "Tierra Propia" se habían regularizado 40 mil lotes en zonas donde la organización creada por los brigadistas de Política Popular tenía presencia. ${ }^{22}$ Con esa estrategia el gobierno acotó el crecimiento del movimiento urbano popular en Monterrey.

\section{La Laguna: el semillero de la revolución}

Para 1976 la organización se había extendido a otras regiones del país, en especial a la Comarca Lagunera. Se tejieron redes con el trabajo pastoral que entonces realizaban algunas parroquias de colonias populares tanto en Gómez Palacio, Durango como en Torreón, Coahuila entre 1970 y 1972. Los brigadistas maoístas y los párrocos que seguían la opción preferencial de los pobres encontraron puntos de coincidencia en su labor. Esta relación fue crucial más adelante, pues permitió que brigadistas de Política Popular construyeran una cabeza de playa en el sur del país.

No queda claro cuándo llegaron los brigadistas de Política Popular a Torreón. Por una parte, Salvador Hernández Vélez, uno de los militantes laguneros reclutados dentro del movimiento estudiantil, cree que Hugo Andrés Araujo arribó, proveniente de Sonora, a la

${ }^{21}$ Diana R. Villarreal yVíctor Castañeda, Urbanización y autoconstrucción de vivienda en Monterrey, México, D.F., Centro de Ecodesarrollo, 1986, 68.

${ }^{22}$ Ibid., 58.

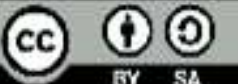


Jorge Puma, Los maoístas del norte de México: breve historia de Política Popular-Línea Proletaria, 1969-1979 / Maoists of Northern Mexico: A Short History of Política Popular-Línea Proletaria, 1969-1979, Revista Izquierdas, 27, abril 2016, ISSN 0718-5049, pp. 200-229

región entre 1971 y $1972 .{ }^{23}$ Por otra parte, Orive relata que su incursión en Torreón vino de la mano de una difícil relación con José Batarse Charur quien por ese entonces era un cura diocesano encargado de una parroquia en el municipio de Francisco I. Madero en las cercanías de Torreón. El proceso comenzó entre 1972 y 1973. El intentó prosperó y la relación con el cura Batarse mejoró, lo cual permitió que se fortaleciera el movimiento urbano en la Laguna. La sinergia entre los brigadistas y la pastoral derivó en dos procesos: 1) la fundación de las colonias populares en Torreón y 2) la transformación del la finca vitivinícola Batopilas en un ejido colectivo gestionado por los propios trabajadores agrícolas. ${ }^{24}$ Luego de la expulsión de Batarse de Torreón en octubre de 1976, Orive y las brigadas de Política Popular se relacionaron con Samuel Ruíz, obispo de San Cristóbal, e iniciaron su trabajo en Chiapas.

Otro elemento que coadyuvó a transformar la Laguna en el semillero de militantes de Política Popular fue la efervescencia estudiantil en la zona. Desde 1971 tanto en Torreón como en Gómez Palacio existió un fuerte movimiento estudiantil que, entre otras cosas, pugnaba por la creación de espacios universitarios. Poco a poco, varios de los recién politizados estudiantes emprendieron un proceso de radicalización que les hizo relacionarse con la insurgencia sindical que en esos momentos luchaba contra el "charrismo". ${ }^{25}$ La relación con disidentes del sindicato ferrocarrilero y electricistas de la tendencia democrática les enseñó una cultura de democracia directa, así como las tácticas básicas de movilización popular (por ejemplo, los mítines relámpago). ${ }^{26}$ Cuando Hugo Andrés Araujo entró en contacto con ese inquieto grupo de jóvenes, las condiciones estaban dadas para su captación en las filas del maoísmo popular. El resultado de este encuentro fue el surgimiento de varios cuadros políticos que combinaron su formación previa en el movimiento estudiantil y popular con la orientación maoísta de Política Popular.

En Torreón el maoísmo halló un terreno nutrido con el paciente trabajo pastoral de un grupo de sacerdotes diocesanos que habían optado por atender los problemas económicos y espirituales de sus feligreses más necesitados. Estos sacerdotes desarrollaron su actividad pastoral dentro del área rural colindante a Torreón como parte de un movimiento que estaba trastocando las viejas relaciones entre la Iglesia Católica, la burguesía y el gobierno no sólo en la región, sino en México y América Latina. Después del

\footnotetext{
${ }^{23}$ Salvador Hernández Vélez (militante de Política Popular en Torreón, Coahuila), entrevistado por Jorge Puma, Saltillo, Coahuila, 12 de agosto de 2013.

${ }^{24}$ Adolfo Orive (líder de Política Popular), entrevistado por Jorge Puma, México, D.F., 18 de octubre de 2012.

${ }^{25}$ El término "charro" en referencia al sindicalismo deriva del episodio denominado "charrazo" cuando en 1948 el Gobierno mexicano impuso a una directiva diferente a la electa al frente del sindicato ferrocarrilero. Lo anterior porque el líder impuesto, Jesús Díaz de León, era apodado "charro" por su afición a la charrería. A partir de entonces se denomina "charro" a todo líder sindical impuesto y/o respaldado por el Estado. Véase Barry Carr, La izquierda mexicana a través del siglo XX, México, D.F., Ediciones ERA, 1996, 177-179.

26 José Augusto Sánchez Galindo "Guti” (militante de Política Popular en Gómez Palacio, Durango), entrevistado por Jorge Puma, Gómez Palacio, Durango, 28 de agosto de 2013.
} 
Jorge Puma, Los maoístas del norte de México: breve historia de Política Popular-Línea Proletaria, 1969-1979 / Maoists of Northern Mexico: A Short History of Política Popular-Línea Proletaria, 1969-1979, Revista Izquierdas, 27, abril 2016, ISSN 0718-5049, pp. 200-229

Concilio Vaticano II (1962-1965) y del surgimiento de la Teología de Liberación, México fue el escenario de varios movimientos dentro de la Iglesia Católica que pueden denominarse, de forma genérica, el auge de la izquierda.

En estos movimientos clérigos y laicos se replantearon su compromiso con la institución y sus miembros. Los ejemplos de esta nueva concepción del catolicismo social son bastante descriptivos: desde el replanteamiento de las Juventudes Obreras Católicas que condujo a la fundación de un activo Frente Auténtico del Trabajo (FAT) hasta los Sacerdotes por el Socialismo y Monseñor Méndez Arceo. ${ }^{27}$ Así, el cristianismo se transformó en una doctrina explosiva y revolucionaria. El aspecto central de esta nueva concepción de la labor pastoral era la tríada ver-juzgar-actuar, un método en el cual la labor de los católicos se traslapó pronto con la de los jóvenes aprendices de revolucionarios.

A partir de 1972, en La Laguna los padres Benigno Martínez, José Batarse, Jesús de La Torre, Armando García y Natividad Fuentes, con la venia de su obispo Fernando Romo Gutiérrez, iniciaron su trabajo social en favor de los colonos pobres de los ejidos laguneros. Durante ese proceso apoyaron a los colonos en sus reivindicaciones y sufrieron el acoso de las autoridades locales hasta que en 1976, dentro del contexto de invasiones de tierras en San Pedro, Coahuila, se giró un orden de aprehensión en contra de los sacerdotes Batarse, García, Fuentes y de la Torre. El 14 de octubre de 1976, el padre Benigno Martínez, quien también apoyaba el movimiento, fue detenido junto con Hugo Andrés Araujo y 30 colonos. Fue liberado el 19 de octubre tras ser golpeado por la policía durante su detención. ${ }^{28}$ La oligarquía local y el gobierno estatal buscaron que el obispo retrocediera en su apoyo al experimento progresista. El contacto de estos curas con los activistas movilizados por Política Popular trascendió el discurso, al grado de convertirse en militantes de la organización. La experiencia del compromiso eclesiástico con los movimientos populares, fue otro elemento que marcó la experiencia de Política Popular cuando sus brigadistas se trasladaron al sur del país.

Esta doble conexión, con el movimiento estudiantil y la pastoral popular, llevó a los brigadistas de Política Popular a encabezar un amplio movimiento de ocupación de terrenos y de formación de "colonias independientes". En plena migración del campo a la ciudad los brigadistas construyeron una serie de colonias a partir de su implantación en los terrenos de "Tierra y Libertad". El modelo que ya había dado resultados en Durango fue replicado paulatinamente en Torreón, Gómez Palacio y San Pedro. El aire revolucionario de esos días pervive en la nomenclatura de varias colonias laguneras: División del Norte, Flores Magón, Rubén Jaramillo, Jacinto Canek y 2 de marzo. Estos nombres siguen ahí como testimonio

\footnotetext{
${ }^{27}$ Miguel Concha Malo et al., La participación de los cristianos en el proceso popular de liberación en México, México, D.F., Siglo XXI, 1986, 85-115.

${ }^{28}$ Ibid., 153-155.; "Otros seis detenidos, uno de ellos sacerdote, en relación con las invasiones," en El Siglo de Torreón, 16 de octubre de 1976; y "Hay orden de detención contra varios sacerdotes en San Pedro," en El Siglo de Torreón, 18 de octubre de 1976.
} 
del radicalismo y del auge de un movimiento popular. Ahora bien, hay que resaltar que el movimiento enfrentó menos represión en Torreón que en Gómez Palacio, aunque algunos de sus cuadros dirigentes, como Hugo Andrés Araujo, terminaron encarcelados y a fines de 1976 el cura Batarse tuvo que exiliarse durante dos meses. ${ }^{29}$

La labor de la organización vista a distancia es impresionante: reparto equitativo de terrenos, integración de los estudiantes en las colonias, construcción de dispensarios médicos y estructuras productivas (tiendas, tortillerías, etc.). La mística de la participación era tal que los testimonios de los colonos hablan de un ansia de participar en las maratónicas asambleas generales o en las pequeñas asambleas de manzana. En esas asambleas, surgió un nuevo tipo de brigadista, el brigadista popular, que ya no era el estudiante radicalizado, sino el colono que había acudido al movimiento atraído por la promesa de un terreno. Ese colono joven, en muchos casos empujado por su pareja, se integró a las filas de Política Popular y extendió las formas de la organización a otras colonias y a sus fuentes de trabajo. Eso explica cómo ciertos elementos de democracia directa y demandas de autonomía sindical permearon sectores como el de limpieza municipal y el de los jornaleros de Batopilas. ${ }^{30}$ En La Laguna se desarrolló un nuevo tipo de militante que cuando salió de su territorio fue considerado por algunos sectores estudiantiles como "lumpen", pero que dentro de los objetivos del maoísmo de Política Popular era el prototipo de militante proletario.

La creación del ejido colectivo Batopilas fue en su momento el mayor éxito de la alianza de actores "revolucionarios" en la Laguna. Resultó de la organización de los obreros agrícolas de la empresa vitivinícola Batopilas por parte de militantes estudiantiles y colonos populares de La Laguna; no obstante, también fue un producto del apoyo fortuito del gobernador Flores Tapia, quien se encontraba enfurecido por la actitud de los dueños de la empresa. ${ }^{31}$ La huelga culminó en la expropiación de la hacienda vitivinícola y la conversión de sus trabajadores en ejidatarios. Con una cosecha a punto de perderse, los campesinos recibieron el apoyo masivo de caravanas de colonos de Tierra y Libertad y otras colonias populares. Se inició un experimento de organización colectiva que hoy continúa a pesar de los problemas que enfrenta la región.

\section{Lucha a muerte contra la socialdemocracia}

En el marco de la expansión de Política Popular y la llegada de Orive y algunos militantes

\footnotetext{
29 José Augusto Sánchez Galindo "Guti” (militante de Política Popular en Gómez Palacio, Durango), entrevistado por Jorge Puma, Gómez Palacio, Durango, 28 de agosto de 2013. y Adolfo Orive (líder de Política Popular), entrevistado por Jorge Puma, México, D.F., 18 de octubre de 2012.

${ }^{30}$ Roberto Guevara y Dolores Cháirez (militantes populares de Política Popular en la colonia Tierra y Libertad de Torreón), entrevistados por Jorge Puma, Torreón, Coahuila, 26 de agosto de 2013.

${ }^{31}$ Idem. y José Augusto Sánchez Galindo “Guti” (militante de Política Popular en Gómez Palacio, Durango), entrevistado por Jorge Puma, Gómez Palacio, Durango, 28 de agosto de 2013.
} 
Jorge Puma, Los maoístas del norte de México: breve historia de Política Popular-Línea Proletaria, 1969-1979 / Maoists of Northern Mexico: A Short History of Política Popular-Línea Proletaria, 1969-1979, Revista Izquierdas, 27, abril 2016, ISSN 0718-5049, pp. 200-229

laguneros a Monterrey en 1976, comenzaron las luchas por el control de la organización. Las diferencias sobre el liderazgo, así como las posiciones ideológicas y estratégicas, provocaron una fractura entre el grupo liderado por Orive y el ya asentado en Monterrey y Durango en las colonias populares. El grupo de Orive planteaba la continuación de un modelo asambleísta para la toma de decisiones. El grupo de Alberto Anaya respondía que en la práctica ese sistema implicaba la centralización de la dirección en una sola la persona: Orive. Como era la usanza de la izquierda de la época, ambas facciones expresaron su desacuerdo con sendos documentos doctrinales en los que apelaban a las líneas teóricas del maoísmo. En el caso de Línea Proletaria esto significaba que:

[...] una lucha por meter agua a la colonia o por construir la escuela tiene que estar discutida por las manzanas, decidida por la Asamblea General, coordinada según un programa por los comisionados del organismo ejecutor y llevada a cabo principalmente por nuestros propios esfuerzos, es decir, por el trabajo de las masas... Al final de la lucha nos va a importar más la organización nuestra que el agua que metimos. ¿Por qué nos va a importar más la organización que el agua? Porque con la organización podemos seguir resolviendo todas nuestras necesidades, inclusive podemos transformar la sociedad y derrotar a la burguesía y al gobierno, y sin la organización no podemos resolver nada por nosotros mismos; seguimos dependiendo de líderes y gobierno. ${ }^{32}$

Como puede apreciarse, hay un ataque a la posición política del grupo de Anaya, la cual mantenía un esquema teórico más cercano al documento original de "Hacia una Política Popular" y seguía un maoísmo más ortodoxo en lo organizativo. Asimismo, Línea Proletaria criticó las implicaciones prácticas de los "socialdemócratas" de Anaya, quienes ponían énfasis en la resolución de los problemas de los colonos sobre el trabajo organizativo político. Parece ser que esta crítica tocaba un punto sensible en la actuación política del grupo que luego se autodenominaría "Línea de Masas", pues Haber señala que: "el CDP [Comité de Defensa Popular, la organización afín al grupo de Anaya en Durango] no ha estimulado los procesos de tomas de decisiones colectivas, sino que más bien cuenta con el apoyo de la base a las decisiones de la dirigencia, que descienden por la organización para su consulta y ratificación. "33 Paradójicamente, este elemento de subordinación de las bases a la dirección de antiguos militantes de Política Popular representó un progresivo alejamiento de la filosofía organizativa que había impulsado la creación de esta agrupación.

Por otro lado, la crítica a las posiciones de Orive se hacía por una pretendida

\footnotetext{
32 Anónimo, "¿Qué es la Línea Proletaria?," en Rebelión en Chiapas. Una antología histórica, ed. John Womack Jr., México, D.F., Random House Mondadori, 2009, 259.

${ }^{33}$ Paul Lawrance Haber, op. cit., 59.
} 
Jorge Puma, Los maoístas del norte de México: breve historia de Política Popular-Línea Proletaria, 1969-1979 / Maoists of Northern Mexico: A Short History of Política Popular-Línea Proletaria, 1969-1979, Revista Izquierdas, 27, abril 2016, ISSN 0718-5049, pp. 200-229

radicalidad de sus acciones en Monterrey en febrero de 1976 y sus conexiones con altos funcionarios del gobierno federal de la época. Héctor Camero, uno de los fundadores de la colonia Tierra y Libertad en Monterrey y cercano al grupo de Anaya en los años setenta, relató en 1994 a la revista "Proceso" que:

[...] nos dimos cuenta con mayor claridad [durante la época que Orive residió en Monterrey] que tenía relaciones política al más alto nivel, incluidos el presidente Echeverría y su secretario de Gobernación, Mario Moya Palencia. Además de elaborar los documentos de PP [Política Popular], Orive tenía como función explícita conseguir recursos para el movimiento, de cuyo origen los brigadistas teníamos sólo indicios; traía, por ejemplo, vehículos de Las Truchas [la siderúrgica manejada en esa momento por el padre de Orive]. El contacto de Orive y Anaya con Echeverría fue el rector de la UANL, Luis Eugenio Todd. ${ }^{34}$

Estas acusaciones parecen fundarse en las relaciones personales de Adolfo Orive, quien proviene de una familia perteneciente a la elite posrevolucionaria. Sin embargo, la crítica resulta extraña como veremos más adelante, pues la "Línea de Masas" tampoco tuvo una postura intransigente en sus tratos con el Estado. Después de todo, fue a través de la negociación con los gobiernos del PRI en Durango y Nuevo León que logró concesiones de tierras para instalar sus colonias. Ahora bien, la acusación más dura contra Orive respecto a sus actividades en Monterrey está relacionada con los sucesos del 18 de febrero de 1976 cuando seis colonos murieron en un enfrentamiento con la policía por el presunto robo de material eléctrico. Camero señala que:

Orive inició aquí [Monterrey] su revolución cultural con el planteamiento de que había que librar una lucha a muerte contra la socialdemocracia representada por Anaya-, ya que ponía a los dirigentes encima de las masas; son estas, decía Orive, las que deben conducir los movimientos. Señalaba que los dirigentes que no enseñan esos métodos son burgueses, socialdemócratas que deben ser barridos por las masas. Y así nos fue llevando la lucha ideológica a extremos enconados, terribles. ${ }^{35}$

Esta crítica contrasta con el talante usualmente negociador del fundador de Política Popular, pero que presenta indicios de una temprana radicalización, la cual hace recordar ciertos elementos del maoísmo francés después de mayo del 1968. En cambio, en la versión

\footnotetext{
${ }^{34}$ Antonio Jaquez, "Hablan tres fundadores del movimiento Tierra y Libertad. Los apoyos de Línea de Masas: Echeverría, Moya Palencia, Manuel Camacho, Lozoya, Raúl Salinas de Gortari," en Proceso, México, D.F., 24 de enero de 1994.

${ }^{35}$ Idem.
} 
de Orive fueron los simpatizantes de Anaya y Camero quienes recurrieron a la violencia en esas jornadas, al punto de que su integridad estuvo en peligro y sólo la intervención de simpatizantes suyos de las colonias populares lo puso a salvo. ${ }^{36}$ En este punto de la investigación es imposible emitir un juicio sobre la veracidad de las declaraciones de ambas partes, de cualquier modo, lo que sucedió en seguida descartó un posible proceso de radicalización.

\section{Línea Proletaria: de las colonias a los sindicatos}

Tras la separación del grupo de Anaya, Orive y sus partidarios siguieron un camino mixto. Su organización, a la que calificaron como "Línea Proletaria", reorientó varias veces sus derroteros políticos. Por un lado, se continuó con la infiltración en el emergente movimiento campesino al interior de Durango en la zona de los "llanos de Victoria" y con la participación en la creación de nuevas uniones de ejidos en Sonora, Guerrero y Chiapas. Por el otro, aunque en constante pugna con grupos trotskistas y comunistas, Línea Proletaria cobró fuerza dentro de la disidencia magisterial que posteriormente se constituiría como el magisterio democrático de la Coordinadora Nacional de Trabajadores de la Educación. En ese mismo sentido, se infiltró con éxito en el Sindicato Minero al punto de casi conseguir su control.

Su conexión con las empresas siderúrgicas, en especial con la empresa "Altos Hornos" en Monclova, Coahuila, fue un subproducto de su expansión en las colonias populares del norte del país. ${ }^{37}$ En un principio fueron cuadros estudiantiles que trabajan con colonos y obreros de Monclova quienes empezaron a infiltrarse en "Altos Hornos", la cual entre 1942 y 1970 fue la empresa fundidora de acero más importante de América Latina pues su producción alcanzaba hasta las 1.5 millones de toneladas de acero líquido al año. Se trataba de una empresa privada fundada con capital norteamericano, pero que el gobierno de Luis Echeverría nacionalizó en $1970 .{ }^{38}$

La influencia de Línea Proletaria en el sector metalúrgico y minero comenzó antes del rompimiento con el grupo de Anaya cuando un grupo de brigadistas originarios de la Laguna intentó influir dentro de la sección 147 del sindicato minero en la empresa "Altos Hornos". No obstante, al evaluar las condiciones imperantes en ese momento, decidieron trasladar su lucha a la organización de los colonos de las afueras de Monclova donde vivían las familias de los trabajadores. Con el triunfo de sus iniciativas por la obtención de servicios (luz, agua, etc.) el prestigio de los militantes de Política Popular entre los

\footnotetext{
${ }^{36}$ Adolfo Orive (líder de Política Popular), entrevistado por Jorge Puma, México, D.F., México, D.F., junio de 2012.

37 Luz María Morales (militante Política Popular y abogada del sindicato minero en Altos Hornos), entrevistada por Jorge Puma, Torreón, Coahuila, 30 de agosto de 2013.

${ }^{38}$ Véase Servando Chávez Quezada, "Notas sobre la historia de AHMSA, 1941-1992," en Tras las huellas de la privatización. El caso de Altos Hornos de México, México, D.F., Siglo XXI, 1994, 60-102.
} 
trabajadores aumentó y se inició un proceso de propaganda y organización hasta conformar el grupo "Primero de Mayo" o "Planilla Blanca". Entre 1972 y 1977 este grupo se consolido como la dirigencia sindical de la sección 147 del sindicato minero, desplazando a los grupos corruptos afines al PRI. El éxito de esta iniciativa, a través de luchas por la renivelación salarial y créditos de los trabajadores, alcanzó su culmen en las negociaciones con la patronal a inicios de la década de los ochenta y con la consecuente obtención de cierto grado de administración conjunta. De este proceso se derivó la creación de consejos de sector formados por empleados, técnicos y dirección, los cuales determinaban las metas de productividad por consenso y significaron para los trabajadores una verdadera apropiación de su trabajo. ${ }^{39}$

El fin de esta experiencia sindical de Línea Proletaria, luego de su derrota en las negociaciones contractuales de 1977, coincidió con el cambio de orientación del modelo económico en México. Con todo, hay que considerar que el éxito de los militantes de Línea Proletaria en Monclova sobrepasó los límites de la sección 147 y se extendió a los trabajadores de la Fundidora de Monterrey donde también conquistaron la dirección sindical. Al año siguiente esta alianza desafió el dominio del líder "charro" Napoleón Gómez Sada sobre el Sindicato Minero, mas fue aplastada por las maniobras del "charrismo" y sus militantes acabaron expulsados del sindicato. Ahora bien, Monclova y Monterrey no fueron los únicos espacios donde el trabajo de Línea Proletaria prosperó dentro del sindicato minero. También en la siderúrgica de Lázaro Cárdenas, Michoacán, los militantes de Línea Proletaria provenientes de Torreón lograron ganar espacios dentro de la sección 271 del sindicato minero donde se presentaban a sí mismos como "Línea de Masas" y donde contaron con el respaldo del líder obrero Rafael Melgoza. ${ }^{40}$

Un aspecto importante en la labor de los activistas de Política Popular en el sindicalismo minero fue su intento de aplicar el método de "pretextos-objetivos". Es decir, los brigadistas integrados en las siderúrgicas buscaban que sus actividades sindicales en torno a la mejora de las condiciones laborales y la lucha intrasindical contra el "charrismo" dieran pie a la construcción de una conciencia proletaria y no se quedaran en una mera lucha económica. Además, esa lucha prolongada y por etapas tenía como objetivo a mediano plazo arrebatar pedazo a pedazo terreno al "enemigo".

Durante ocho años -once, en el caso de Lázaro Cárdenas-, los militantes de Línea Proletaria y sus aliados dentro del sindicato resistieron el acoso del gobierno con el apoyo de movimientos populares de colonos y organizaciones campesinas afines hasta que finalmente fueron despedidos de la empresa. Los avances en conquistas sindicales de la década anterior se perdieron y la lucha democrática terminó con la cooptación de varios de

\footnotetext{
${ }^{39}$ Adolfo Orive y José Luis Torres, Poder Popular. Construcción de ciudadanía y comunidad, México, D. F., Juan Pablos-Fundación México Social Siglo XXI, 2010, 411-506.

${ }^{40}$ Illán Bizberg, La acción obrera en Las Truchas, México, D.F., Colegio de México, 1982, 64-67.
} 
los antiguos sindicalistas por parte del PRI. ${ }^{41} \mathrm{El}$ destino del sindicalismo independiente en el sector siderúrgico se selló con el ocaso del viejo modelo económico nacionalista que trajo consigo la privatización y con ello el despido masivo de trabajadores.

\section{Chiapas: los norteños en tierra maya}

La historia de Política Popular en Chiapas es producto de su trabajo en La Laguna y de la incorporación dentro de Línea Proletaria del ala no guerrillera de Unión del Pueblo, un grupo de izquierda fundado en la entonces Escuela Nacional de Agricultura con sede en Chapingo. Son dos trayectorias paralelas de grupos maoístas que terminan por cruzarse en 1976 cuando los militantes de Unión del Pueblo se incorporan a Línea Proletaria.

Los "chapingueros" de Unión del Pueblo, como René Gómez Orantes, tenían tiempo trabajando en las comunidades chiapanecas en la estela del Congreso Indígena de 1974. Su relación con la diócesis de San Cristóbal les permitió introducirse en las comunidades indígenas y realizar trabajo político para formar cuadros y bases de apoyo. Por su parte, el grupo de Orive contactó al obispo Samuel Ruíz de San Cristóbal en el marco de su apoyo al párroco José Batarse en Torreón. Cuando Batarse tuvo que huir de Torreón, encontró refugio en Chiapas, gracias a lo cual la recién formada Línea Proletaria pudo enviar allí a una brigada de activistas laguneros a cargo de Javier Gil. De los cuales, según cuenta el propio Gil, al menos uno era de extracción popular. ${ }^{42}$ El encuentro de los dos grupos maoístas resultó en la incorporación de una buena parte de Unión del Pueblo en Línea Proletaria y su traslado al norte del país. ${ }^{43}$ Para 1975 , se habla de diecinueve brigadistas coahuilenses y seis brigadistas defeños de Política Popular en Chiapas. ${ }^{44}$ Los "norteños" entraron a Chiapas para orientar el trabajo campesino. En ese momento comenzó un mito alimentado por sus enemigos.

El Chiapas donde trabajaron los brigadistas de Unión del Pueblo-Línea Proletaria estuvo marcado por la efervescencia campesina, la activa pastoral indígena de la DSC y los ecos de las guerras civiles centroamericanas. Sin ignorar el componente de formación de identidad étnica, el proyecto de una Iglesia Popular es la clave para entender la manera en que se creó un amplio movimiento de masas orientado por activistas maoístas. El movimiento abarcó el territorio de la DSC, pero fue más allá hasta abarcar otras regiones del estado.

\footnotetext{
${ }^{41}$ Enrique García Márquez, "La privatización de Altos Hornos de México," Trabajo y Democracia, no. 104 2009. y Salvador Corro, "El gobierno desecha una herencia de Lázaro Cárdenas," en Proceso, México, D.F., 19 de marzo de 1990.

42 Javier Gil (militante fundador de Política Popular), entrevistado por Jorge Puma, México, D.F., 30 de septiembre de 2013.

${ }^{4}$ Véase María del Carmen Legorreta Díaz, Religión, política y guerrilla en Las Cañadas de la Selva Lacandona, México, D.F., Cal y Arena, 1998, 109.

${ }^{44}$ Carlos Manuel Valdés Dávila (militante de Unión del Pueblo y Política Popular en Chiapas), entrevistado por Jorge Puma, Saltillo, Coahuila, 13 de agosto de 2013.
} 
Jorge Puma, Los maoístas del norte de México: breve historia de Política Popular-Línea Proletaria, 1969-1979 / Maoists of Northern Mexico: A Short History of Política Popular-Línea Proletaria, 1969-1979, Revista Izquierdas, 27, abril 2016, ISSN 0718-5049, pp. 200-229

Un ejemplo, quizá fortuito, de la integración entre maoísmo, teología de la liberación, orígenes clasemedieros en Coahuila y la experiencia de estudiar en el exterior es el caso de Carlos Manuel Valdés Dávila. El Dr. Valdés Dávila, actualmente historiador especializado en el norte de México, estudió teología en Lovaina siete años dentro de su preparación para ordenarse sacerdote. En el ambiente revolucionario de finales de los años sesenta abandonó, junto con buena parte de su generación, sus estudios y regresó a México para hacer trabajo con la "gente pobre". Marchó hacia Chiapas donde trabajó con la DSC, pero lo dejó al cabo de un año "porque pensamos que era rollo, rollo... vivan los pobres, y no, no había trabajo fundamental. Era el trabajo catequista. Yo pienso que la Diócesis era una especie de panfleto." 45 Ante esa situación su reacción, junto con la de varios activistas, fue acercarse a Unión del Pueblo. El Dr. Valdés ya había estado expuesto a las ideas maoístas durante sus estancia en Europa así que su integración a este grupo fue rápida. Hasta ahora Valdés sostiene que el maoísmo no fue un obstáculo en su quehacer con las comunidades. Al contrario, opina que a diferencia de otros grupos de izquierda la lógica maoísta de integrarse al pueblo generó una mejor estrategia de trabajo con las comunidades.

De acuerdo con Valdés, integrarse a las comunidades no fue sencillo. No obstante, su participación en la resolución del problema del transporte local fue su puerta de entrada, asimismo su disposición a aprender la lengua de los habitantes le permitió ser aceptado. Hay que recalcar que incluso ahora rechaza la idea de vanguardismo que permeaba en ese entonces, y que por momentos sigue permeando, en el trabajo de muchas organizaciones de izquierda al relacionarse con campesinos e indígenas. Por ejemplo, cuando alfabetizó, lo hizo en lengua tojolabal y acabó por alejarse del método de Freire pues consideró incorrecta la idea de que se concientizaría al "campesino" desde afuera. En ese sentido, Valdés no es más que otra muestra paradójica de la actitud anti elitista de los brigadistas de orientación maoísta.

La trayectoria de Carlos Valdés dentro de Línea Proletaria no termina en Chiapas. En 1979, a solicitud del líder de la Unión de Uniones, Salvador Pérez Díaz, se trasladó a Sonora para trabajar con un equipo de estudiantes sonorenses en las comunidades Yaquis. Gracias a esta conexión Línea Proletaria habría luego de volver al norte para trabajar con la Coalición de Ejidos del Valle del Yaqui. Esa historia puede leerse en el libro de Gustavo Gordillo, Campesinos al Asalto del Cielo. ${ }^{46}$

La otra cara, muchas veces oculta por su ruptura final en 1979, es la fascinación de la Diócesis de San Cristóbal con el movimiento popular en la Laguna. Según Jesús Morales Bermúdez, filósofo originario de Chiapas, no sólo Batarse y las colonias populares figuran en las elogiosas declaraciones de los órganos de difusión de la DSC. Batopilas, como

\footnotetext{
${ }^{45}$ Ibid.

${ }^{46}$ Para una visión crítica a la labor de los brigadistas de Política Popular en los ejidos colectivos del Valle del Yaqui véase Gustavo Gordillo, Campesinos al asalto del cielo. Una reforma agraria con autonomía, México, D.F., Siglo XXI, 1988, 159-161.
} 
Jorge Puma, Los maoístas del norte de México: breve historia de Política Popular-Línea Proletaria, 1969-1979 / Maoists of Northern Mexico: A Short History of Política Popular-Línea Proletaria, 1969-1979, Revista Izquierdas, 27, abril 2016, ISSN 0718-5049, pp. 200-229

movimiento campesino autogestionario, aparece como un referente en la revista de $E l$ Caminante de 1977 publicada por la DSC. Los contactos entre la Diócesis, los activistas norteños y Orive pasaron por una corta luna de miel de un año, hasta que la Iglesia temió perder el control sobre la zona. ${ }^{47}$ Legorreta, usando testimonios de ex brigadistas de Línea Proletaria, explica ese rompimiento como el resultado de una aplicación mecánica de la línea política de la organización que no tomó en cuenta las condiciones particulares de las Cañadas. Legorreta afirma que los brigadistas norteños venían de su conflicto con la "línea socialdemócrata" en Nuevo León y por eso eran muy sensibles ante cualquier atisbo de "liderazgo natural", como era el caso de los catequistas. Entonces, atacaron la estructura montada por la Iglesia Católica en las comunidades indígenas al considerarla elitista y antidemocrática, en cambio, impulsaron el sistema asambleario que habían usado en el norte del país. La reacción de la Diócesis en 1979 no se hizo esperar: retiró su apoyo a los brigadistas y buscó su expulsión de las comunidades. El resultado fue catastrófico para la expansión de Política Popular en Chiapas, pues los brigadistas tuvieron que desplazarse a otras zonas abiertas al trabajo político fuera del control de la DSC. En consecuencia, las comunidades de las Cañadas de la selva Lacandona quedaron sin apoyo ni orientación política, pues la DSC no atendió sus demandas prácticas de lucha por la tierra y la producción. ${ }^{48}$ Estos hechos abren un flanco de ataque a la visión comúnmente aceptada del trabajo de la Diócesis con las comunidades de las Cañadas.

Los vaivenes en la relación entre la DSC y Línea Proletaria no impidieron que los asesores maoístas aprovecharan las coyunturas de carácter político y económico dentro de las comunidades para fomentar la organización campesina. Después del Congreso Indígena de 1974 los brigadistas maoístas de Unión del Pueblo/Línea Proletaria generaron una serie de programas productivos en respuesta a las necesidades de las comunidades. Junto con cursillos sobre lucha de clases e historia de la Revolución mexicana, los brigadistas impulsaron un programa de Bodega-Avión-Camión (BAC). ${ }^{49}$ La versión chiapaneca del socialismo como lucha de clases más electrificación entró en escena.

En esta campaña de organización de las comunidades campesinas chiapanecas se reflejaron los principios maoístas desarrollados en las experiencias anteriores de Política Popular. Un régimen de asambleas y democracia directa junto con direcciones colegiadas rotativas fueron su sello distintivo. Marco Estrada, investigador de la zona tojolabal, habla de la etapa de las "comunidades republicanas de masas" dentro de la evolución política de las comunidades indígenas tojolabales. En muchos casos, se trató de una etapa de tránsito

\footnotetext{
47 Véase Jesús Teófilo Morales Bermudez, Pensamiento y catolicidad en Chiapas: la diócesis de San Cristóbal de las Casas 1950-1995, Escuela Nacional de Antropología e Historia, 2004, 168-171.

${ }^{48}$ Legorreta Díaz, op. cit., 109-115.

${ }^{49}$ Ibid., 72. y Carlos Manuel Valdés Dávila (militante de Unión del Pueblo y Política Popular en Chiapas), entrevistado por Jorge Puma, Saltillo, Coahuila, 13 de agosto de 2013.
} 
Jorge Puma, Los maoístas del norte de México: breve historia de Política Popular-Línea Proletaria, 1969-1979 / Maoists of Northern Mexico: A Short History of Política Popular-Línea Proletaria, 1969-1979, Revista Izquierdas, 27, abril 2016, ISSN 0718-5049, pp. 200-229

entre la comunidad cristiana politizada y la base de apoyo rebelde de los últimos años. ${ }^{50}$ Una vez más la idea de que la política debía hacerse por las masas para las masas estaba en el fondo del proyecto político-organizativo de la alianza entre brigadistas y comunidades.

Neil Harvey, en sus escritos previos al levantamiento zapatista, sostenía que en una primera etapa los intentos de organización se beneficiaron de la política agraria del presidente Echeverría que fomentó la formación de uniones ejidales. Así nacieron entre 1975 y 1976 las primeras organizaciones en el norte de Chiapas y en la selva Lacandona: la Quiptic Ta Lecubtesel ("Unidos por Nuestra Fuerza") en Ocosingo, Lucha Campesina en Comitán y Tierra y Libertad en Las Margaritas. Ese impulso organizativo para mejorar las condiciones de vida de las comunidades indígenas y mestizas se enfrentó pronto a las decisiones del gobierno federal de monopolizar la explotación forestal de una parte de las tierras donde se habían formado estos ejidos. La amenaza externa y el cambio de sexenio trajeron consigo un cambio de orientación, al reclamo de tierras se unió una vez más una vertiente "productivista". 51 El siguiente paso en la evolución del movimiento campesino chiapaneco de orientación maoísta coincidió con la crisis interna de Línea Proletaria, de ahí que la formación de la Unión de Uniones y su posterior división en dos organizaciones rivales hablan tanto de las fortalezas como de las debilidades del modelo de línea de masas en el sector campesino.

Un episodio que suele dejarse de lado en las narrativas sobre el movimiento campesino chiapaneco es el de los otros norteños, los obreros coahuilenses. Línea Proletaria no sólo envió brigadistas de extracción popular, antiguos colonos de sus colonias "independientes", a las comunidades chiapanecas; también propició un intercambio de experiencias entre los campesinos indígenas de Chiapas y los obreros metalúrgicos de Monclova, Coahuila. Valdés relata que en 1981, en el marco de las luchas de la Unión de Uniones con el gobierno estatal, un contingente de obreros de Monclova se enfrentó contra los granaderos chiapanecos. Ése es un ejemplo extremo de un proceso que comenzó con el apoyo de la seccional 147 de Monclova hacia los campesinos chiapanecos. Éste incluyó excursiones de obreros a la selva de Chiapas para brindar asesoría técnica (soldadura, manejo de maquinaria, etc.) y se complementó con las visitas de los líderes de la Unión de Uniones al sindicato minero en Monclova, las colonias populares de la Laguna y los ejidos

\footnotetext{
${ }^{50}$ Véase Marco Estrada Saavedra, "La comunidad republicana de masas: la constitución de las organizaciones campesinas en las cañadas tojolabales (1975-1987)," en La comunidad armada rebelde y el EZLN. Un estudio histórico y sociológico sobre las bases de apoyo zapatista en las cañadas tojolabales de la selva Lacandona (1930-2005), México, D.F., El Colegio de México, 2007.

${ }^{51}$ Neil Harvey, "La lucha por la tierra en Chiapas: estrategias del movimiento campesino," en Movimientos sociales en México durante la década de los 80, ed. Sergio Zermeño y Jesús Aurelio Cuevas Díaz, México, D.F., UNAM, 1990, 195-200. y "La Unión de Uniones de Chiapas y los retos políticos del desarrolo de base," en Autonomía y nuevos sujetos sociales en el desarrollo rural, ed. Julio Moguel, Carlota Botey, y Luis Hernández Navarro, México, D.F., Siglo XXI-CEHAM, 1992, 221.
} 
Jorge Puma, Los maoístas del norte de México: breve historia de Política Popular-Línea Proletaria, 1969-1979 / Maoists of Northern Mexico: A Short History of Política Popular-Línea Proletaria, 1969-1979, Revista Izquierdas, 27, abril 2016, ISSN 0718-5049, pp. 200-229

colectivos de Sonora. ${ }^{52}$ Como se puede apreciar, hay una compleja experiencia de intercambio político horizontal que rompe tanto con la narrativa de movimientos indígenas endógenos como con la idea de un proceso político creado desde el exterior.

La Unión de Uniones Ejidales y Grupos Campesinos Solidarios de Chiapas (Unión de Uniones) fue en su momento la gran apuesta organizativa de los herederos del maoísmo. En el marco de una conferencia con el entonces candidato presidencial Miguel de la Madrid en 1982, los dirigentes de la Unión de Uniones explicaron los orígenes de su organización. Según narran en su ponencia, el proceso comenzó en 1979 como una respuesta al problema de la comercialización del café. A partir de esa lucha, lograron firmar un convenio con el Instituto Mexicano del Café (INMECAFE), la institución gubernamental encargada de controlar el comercio de dicho producto, y en septiembre de 1980 constituyeron formalmente la organización. ${ }^{53}$ Una vez más, la combinación de movilización y negociación recompensaron el esfuerzo conjunto de brigadistas y comunidades. A un año de su fundación, la organización agrupaba a 12 mil familias en 11 municipios de Chiapas y reunía en su seno a las uniones ejidales más grandes del estado (la Quiptic, Lucha Campesina y Tierra y Libertad), así como a varios grupos campesinos independientes. ${ }^{54}$ $\mathrm{Su}$ fuerza política era tal que junto con la Coalición de Ejidos Colectivos del Yaqui fundaron una de las organizaciones campesinas más grandes del país en los años ochenta: la Unión Nacional de Organizaciones Regionales Campesina Autónomas (UNORCA). ${ }^{55}$ El círculo de los esfuerzos campesinos de Política Popular se cerraba a pesar de los conflictos que dos años antes cimbraron su organización nacional.

Antes de proseguir con la historia de Línea Proletaria, hay que recalcar que la posición política de la Unión de Uniones ante el Estado fue controversial dentro del ámbito de la izquierda campesina de la época. A diferencia de otras organizaciones campesinas que eligieron confrontarse con el régimen como si se tratara de un ente unificado, la Unión de Uniones aprovechó para su beneficio las diferencias entre el gobierno federal y el estatal. Un efecto extremo de esto es que mientras la represión y el asesinato de militantes golpeaban duramente a otras organizaciones, la política de "dos caras" blindó relativamente a los militantes de la Unión de Uniones de la acción represiva de las autoridades chiapanecas. ${ }^{56}$ No fueron entonces los esfuerzos represivos del gobierno los que minaron el proyecto de la Unión de Uniones, sino conflictos al interior de la organización

\footnotetext{
${ }^{52}$ Carlos Manuel Valdés Dávila (militante de Unión del Pueblo y Política Popular en Chiapas), entrevistado por Jorge Puma, Saltillo, Coahuila, 13 de agosto de 2013. Véase también Orive y Torres, op. cit., 123-126.

${ }^{53}$ Nuria Costa, UNORCA. Documentos para la historia, México, D.F., Costa-Amic Editores, 1989, 36-38.

${ }^{54}$ Ibid., 36.

55 Véase Luis Hernández Navarro, "La UNORCA: Doce tesis sobre el nuevo liderazgo campesino en México," en Autonomía y nuevos sujetos sociales en el desarrollo rural, ed. Julio Moguel, Carlota Botey, y Luis Hernández Navarro, México, D.F., Siglo XXI editores, 1992, 70.

${ }^{56}$ Neil Harvey, "La Unión de Uniones de Chiapas y los retos políticos del desarrollo de base," en Autonomía y nuevos sujetos sociales en el desarrollo rural, ed. Julio Moguel, Carlota Botey, y Luis Hernández Navarro, México, D.F., Siglo XXI-CEHAM, 1992, 223.
} 
agudizados por la ausencia de mecanismos internos para el procesamiento de controversias entre los brigadistas.

Los ecos del conflicto aún pueden oírse treinta años después en las pequeñas diferencias de tono entre las crónicas de este rompimiento. Tanto las versiones de los partidarios de Orive como las de los asesores de la Uniones de la selva concuerdan en la serie de hechos que condujeron al rompimiento: la lucha por la tierra de la Quiptic, la represión del gobierno estatal, la posterior movilización para contrarrestarla, las diferencias sobre el manejo de la formación de la Unión de Crédito en 1983. Sin embargo, cada una de las parte culpó a la otra del escalamiento de la lucha entre facciones y trasladó a las asambleas de la organización sus desacuerdos políticos.

Legorreta sostiene que el detonante del rompimiento de la organización fueron las quejas de la Quiptic y Tierra y Libertad sobre cómo el grupo cercano a Adolfo Orive constituyó la Unión de Crédito. Para los miembros de las Uniones Ejidales y sus asesores, liderados por René Gómez Orantes, que Orive permitiera que otras organizaciones participaran en la Unión de Crédito sin contar con el capital suficiente y usando pagarés fue razón suficiente para transformar la desazón en conflicto político por el control de la organización. ${ }^{57}$ Por su parte, la versión del grupo afín a Orive acusa a los asesores de los ejidos de la selva de intentar controlar la organización luego del éxito de su movilización contra la represión del gobierno estatal. ${ }^{58}$ Además, como afirma el historiador Jan de Vos, es importante considerar que detrás de este rompimiento también estuvo el recelo de los dirigentes de la Quiptic hacia los asesores norteños, un recelo que se agudizó por el coqueteo de este grupo de antiguos agentes de la pastoral de DSC con la opción armada como vía paralela para alcanzar sus metas. ${ }^{59}$ Entonces, el fracaso de la búsqueda por un acuerdo sobre la localización de la sede y la composición de la dirección de la Unión de Crédito culminaron en la separación formal.

Por un lado, el grupo de Orive conservó el control de la Unión de Crédito Pajal Ya Kac’Tic (“¡Unidos Venceremos!” en tzetzal) y logró que los tojolabales de la Unión de Ejidos Lucha Campesina se mantuvieran dentro de la organización. En sus manos la Unión de Uniones-Unión de Crédito impulsó la comercialización del café; pero, aun así, no pudo sobrevivir al cambio de modelo económico ni a las fluctuaciones en los precios del café a finales de los años ochenta. El proyecto alcanzó a capear esa coyuntura e intentó reorientar su lucha en el contexto del proyecto social del gobierno de Carlos Salinas; no obstante, a los pocos años, torpedeada por las deudas, la falta de apoyo gubernamental y la crisis desatada por el conflicto armado de 1994, la Unión de Uniones se disolvió en sus partes

\footnotetext{
${ }^{57}$ Legorreta Díaz, op. cit., 152-153.

${ }^{58}$ Orive y Torres, op. cit., 135.

${ }^{59}$ Jan de Vos, Una tierra para sembrar sueños. Historia reciente de la Selva Lacandona 1950-2000, México, D.F., Fondo de Cultura Económica, 2002, 264.
} 
constituyentes. ${ }^{60}$

Por el otro lado, el grupo rival se estableció en 1988 como Asociación Rural de Interés Colectivo (ARIC)-Unión de Uniones. Esta organización continuó su trabajo en forma de proyectos productivos ganaderos y agrícolas. Finalmente, gracias a sus alianzas con un sector del gobierno federal encabezado por Manuel Camacho Solís resolvieron el problema de la tierra al conseguir reconocimiento jurídico de las comunidades de la selva como ejidos en 1989. Con ese reconocimiento y su acceso a créditos bancarios, la ARIC parecía, por fin, reconstituir la gran organización de masas de Las Cañadas de la Selva Lacandona. Sin embargo, a principios de los años noventa se agravaron las diferencias internas derivadas de la lucha por el control de las comunidades entre los partidarios del "zapatismo" y sus detractores. Como en el caso de sus competidores de la Unión de Crédito, los problemas económicos también afectaron la viabilidad de su proyecto. Ahora bien, la ARIC sobrevivió de forma unificada hasta el levantamiento de 1994, cuando se dividió entre quienes se mostraron favorables al Ejercito Zapatista de Liberación Nacional y quienes rechazaron el recurso de las armas. Desde entonces, se ha desarrollado un conflicto entre quienes siguieron a los rebeldes, en cierta medida influenciados por la postura de la Iglesia Católica, y los que prefirieron seguir a un sector de los antiguos asesores en su respaldo a la política gubernamental. ${ }^{61}$

La tragedia de la experiencia organizativa de Política Popular en Chiapas es que su progreso acabó drenando su impulso utópico. Al mismo tiempo, la erosión del sistema económico proteccionista destruyó el pretexto sobre el que había fundado la existencia misma de sus organizaciones. La agonía de su enemigo, el viejo Estado corporativo encarnado en el INMECAFE y las regulaciones agrícolas, trajo consigo la imposibilidad de continuar con el proyecto económico de nuevas relaciones de producción "proletarias". Si bien, hacía más de una década que la organización central había muerto, por lo que los militantes y sus asesorados no tuvieron un referente político al cual acudir para darle sentido a la crisis de los principios fundadores.

\section{La OID: el colapso de un intento de centralización}

En su primera etapa, Política Popular se conformó como una confederación de brigadas que a pesar de seguir una línea política común (la línea de masas) no formaron una organización central. Según se desprendía de "Hacia una Política Popular" el primer paso de los brigadistas estudiantiles debía ser su integración con el pueblo y de ahí conformar movimientos de masas de acuerdo con las necesidades populares. Sin embargo, esta política de descentralización fue tornándose cada vez más problemática al crecer los movimientos sociales en el norte del país y con ellos las capacidades políticas de los brigadistas. Desde

\footnotetext{
${ }^{60}$ Véase Orive y Torres, op. cit., 137-182.

${ }^{61}$ Véase Vos, op. cit., 265-281.
} 
enero de 1974 Política Popular intentó disminuir el peso relativo de los cuadros de extracción estudiantil, ahora integrados en las colonias populares, y construir una "organización proletaria". ${ }^{6}$ Como vimos anteriormente, esto derivó en un conflicto con el grupo de Alberto Anaya y la división de Política Popular. En medio de este conflicto Línea Proletaria se configuró en marzo de 1976 alrededor de la idea de una organización ideológica dirigente (OID) como espacio de discusión interno. ${ }^{63}$ La OID se constituyó entonces como un instrumento político de los brigadistas que sería el equivalente funcional del partido, pero sin romper la conexión orgánica con las masas.

En mayo de 1976 Orive propuso que se centralizara la organización y la ideología del grupo. Para ello impulsó el establecimiento de una Comisión Permanente General de la Organización para encauzar el proceso. Lo que pretendía esta reorientación era que las diferencias entre los miembros, que se conceptualizaban en el marco maoísta de la lucha entre una ideología proletaria-revolucionaria y una ideología burguesa-socialdemócrata moderada, se mantuvieran al interior de la organización sin llegar al rompimiento. También buscaban que se conformara una organización que se ciñera a las pautas asamblearias, pero que al mismo tiempo propendiera a la centralización organizativa y homogeneización ideológica. Finalmente, este programa tenía como una de sus metas que la formación teórica saliera de las brigadas y permeara en los trabajadores y colonos.

El esquema funcionó, no sin ciertos problemas, y en junio de 1977 la misma Comisión Permanente propuso que su papel centralizador fuera asumido por una Asamblea de Coordinadoras Regionales. Una vez más se presentó el problema de posibles escisiones. A diferencia del conflicto con el grupo de Anaya, esta vez la Comisión Permanente General decidió que "el aspecto principal debe mutarse de la lucha ideológica a la unidad política". ${ }^{4}$ De ahí que las pugnas internas se vieron incluso como una oportunidad de generar un organización más democrática. La consigna "Unidad Política/Lucha Ideológica" pareció entonces ser la muestra de la madurez de la organización e inauguró un escenario ascendente de crecimiento político con la absorción de Unión del Pueblo y la lucha por el control del sindicato minero.

Para 1979 se hacía obvio que se estaba generando un liderazgo dentro de la organización y que la idea de que fueran las masas mismas las que realizaran los procesos de dirección y formación teórica no estaba sucediendo en la práctica. El año anterior Adolfo Orive fue duramente cuestionado por los brigadistas integrados en las organizaciones campesinas en Chiapas. En 1979 las críticas se hicieron más agudas y el empujón final vino de la recién abierta "zona centro" (Hidalgo y San Luis Potosí) al grado

\footnotetext{
${ }^{62}$ Línea Proletaria, Contextos en los que fueron publicados los folletos de la organización, México, $1977,3-4$.

${ }^{63}$ Línea Proletaria, Formas actuales de centralización, Línea Proletaria, México, 1977.

${ }^{64}$ Línea Proletaria, op. cit., 9.
} 
de que la de permanencia de Orive al frente del proceso organizativo se tambaleó. ${ }^{65}$ Además, el contexto político nacional, con la reforma política de 1977 que abrió espacios de participación electoral para la izquierda, presentó un nuevo problema para las organizaciones de línea de masas. En un intento de atender esta problemática y acorde a los principios anti vanguardistas Orive planteó su renuncia a participar dentro de la Comisión Permanente General (CPG) en febrero de 1979. En un evento extraño dentro de la tradición política mexicana la CPG decidió publicar las actas del debate donde se aceptó dicha renuncia. Como se desprende de ese documento, los activistas "más ideológicamente avanzados" se enfrentaron al dilema de generar un grupo dirigente que mantuviera los principios de superioridad de las masas ya sin la presencia orientadora del fundador. ${ }^{66}$ Desgraciadamente para la organización no lograron resolver la contradicción y a mediados de ese año presentaron su renuncia.

Orive y Legorreta señalan que la decisión de disolver el grupo coordinador de la OID y posteriormente la OID misma fue producto de una pugna entre quienes querían fortalecer la estructura de brigadas y quienes proponían en cambio la construcción de formas más horizontales de organización. ${ }^{67}$ En esas condiciones fue imposible mantener la cohesión de la organización y cada facción siguió su propio camino. Eso significó el fin de la Línea Proletaria como una organización centralizada, aunque no el fin de los activistas de línea de masas.

\section{Conclusiones}

La línea de masas pervivió en casi todos aquellos que la aceptaron como marco ideológico, de tal modo que el trabajo de reorganización de la Confederación Nacional Campesina en los años noventa y del PRI en la Laguna muestran trazos de su enfoque organizativo. Sin embargo, esta pervivencia no implicó el mantenimiento del elemento utópico de la línea de masas como prefiguración de la nueva sociedad. El cambio político que se dio en México durante la década de los ochenta, la irrupción de la clase media panista como factor hegemónico en las sociedades norteñas y la falta de una solución aceptable ante el problema de la participación electoral llevaron a muchos de los ex militantes a tomar posturas pragmáticas y reformistas. Un pragmatismo no exento de un compromiso con los colonos y campesinos con los que trabajaron, eso sí, lejos ya de toda pretensión utópica radical.

En su camino los militantes de Política Popular siguieron al pueblo al que querían servir y en ello fueron congruentes con su deseo de no asumir una postura vanguardista que

\footnotetext{
${ }^{65}$ Agustín Acosta Zavala, op. cit., 115-117 y Hugo Andrés Araujo de la Torre (militante fundador de Política Popular), entrevistado por Jorge Puma, México, D.F., 30 de julio de 2014.

${ }^{66}$ Véase Línea Proletaria, Renuncia irrevocable... consenso en la Coordinadora General, Línea Proletaria, México, 1979.

${ }^{67}$ Orive y Torres, op. cit., 105. y Legorreta Díaz, op. cit., 121-123.
} 
hiciera a las masas tomar decisiones contrarias a sus intereses. El tono amargo de Orive ante este hecho es evidente cuando declara que: "sí me pegó muy fuerte el que la gente dijera que no quería ya una revolución social ¿no? Y... que todo lo que quería era mejores condiciones de vida [...]"68 Esta afirmación resuena en varios de los testimonios recogidos durante la investigación, pero en pocos casos conlleva un acre final. Los actores de este drama siguen vivos, con una pesada carga de decisiones a lo largo de estos años, y con todo, activos en la vida política o social de los entornos donde se mueven.

Como puede verse, Línea Proletaria no siguió el guión maoísta, sino que innovó sus enfoques al respecto de la organización sindical sin abandonar del todo su énfasis en elementos de democracia directa. Se trata de lo que podría calificarse como una reorientación creativa que asumía el espíritu del pensamiento maoísta sin caer en la repetición dogmática ni en el intento de seguir el manual revolucionario. Hay también indicios al final de este experimento de un desgaste de los militantes y su incorporación a gobiernos emanados del PRI, aunque la evaluación de su relación con el régimen es un asunto complejo que no puede leerse de manera automática con la vieja narrativa de la cooptación.

Si la visión común de la historia de la izquierda en México es la de un proceso de paulatino aglutinamiento en torno a la unión de las tradiciones comunista y nacional revolucionaria, estudiar a Política Popular es cuestionar esa visión. Estamos ante una historia con raíces regionales que muestra a una izquierda distinta de la partidaria y de la guerrillera.

\section{Bibliografía}

Acosta Zavala, Agustín. Así lo recuerdo., Torreón, Coahuila: 2015.

- - - "Entrevista a Agustín Acosta brigadista en Tierra y Libertad (Monterrey, Nuevo León)." por Jorge Puma (22 de noviembre 2013).

Araujo de la Torre, Hugo Andrés. "Entrevista a Hugo Andrés Araujo de la Torre miembro fundador de Política Popular." por Jorge Puma (30 de julio 2014).

Bizberg, Illán. La acción obrera en Las Truchas. México, D.F.: Colegio de México, 1982.

Bouchier, Josiane. "La paradoja de la unidad. El movimiento urbano popular y la Coordinadora Nacional del Movimiento Urbano Popular (CONAMUP)." en Movimientos sociales en México durante la década de los 80, editado por Sergio Zermeño y Jesús Aurelio Cuevas Díaz, México, D.F.: UNAM, 1990. 203-220.

Carr, Barry. La izquierda mexicana a través del siglo XX. México, D.F.: Ediciones ERA, 1996.

Concha Malo, Miguel, Óscar González Gari, Lino F. Salas, y Jean-Pierre Bastian. La participación de los cristianos en el proceso popular de liberación en México. Biblioteca

\footnotetext{
${ }^{68}$ Adolfo Orive Bellinger (líder de Política Popular), entrevistado por Jorge Puma, México, D.F., 10 de agosto de 2012.
} 
Jorge Puma, Los maoístas del norte de México: breve historia de Política Popular-Línea Proletaria, 1969-1979 / Maoists of Northern Mexico: A Short History of Política Popular-Línea Proletaria, 1969-1979, Revista Izquierdas, 27, abril 2016, ISSN 0718-5049, pp. 200-229

México: Actualidad y perspectivas. editado por Pablo González Casanova México, D.F.: Siglo XXI, 1986.

Corro, Salvador. "El gobierno desecha una herencia de Lázaro Cárdenas." Proceso, 19 de marzo 1990, 16-21.

Costa, Nuria. UNORCA. Documentos para la historia. México, D.F.: Costa-Amic Editores, 1989.

Chávez Quezada, Servando. "Notas sobre la historia de AHMSA, 1941-1992." en Tras las huellas de la privatización. El caso de Altos Hornos de México, editado por Isabel Rueda Peiro. México, D.F.: Siglo XXI, 1994.

Durán, Ramón. "Veinte Años de Lucha de Masas Parte XIII El triunfo del movimiento de masas es a la vez el inicio de una futura división al interior de la dirección.", El Sol de Durango, 18/03/ 1991.

_-_. "Veinte Años de Lucha de Masas Parte XIV." El Sol de Durango, 22/03/ 1991.

. "Veinte Años de Lucha de Masas Parte XV." El Sol de Durango, 25/03/ 1991.

. "Veinte Años de Lucha de Masas Parte XVI." El Sol de Durango, 29/03/ 1991.

. "Veinte Años de Lucha de Masas Parte XVII." El Sol de Durango, 01/04/ 1991.

. "Veinte Años de Lucha de Masas Parte XXI." El Sol de Durango, 22/04) 1991.

Escudero, Alberto. "Entrevista a Alberto Escudero ex-militante de Política Popular en Durango." por Jorge Puma (26 de junio de 2013).

Estrada Saavedra, Marco. "La comunidad republicana de masas: la constitución de las organizaciones campesinas en las cañadas tojolabales (1975-1987)." Cap. III en La comunidad armada rebelde y el EZLN. Un estudio histórico y sociológico sobre las bases de apoyo zapatista en las cañadas tojolabales de la selva Lacandona (1930-2005). México, D.F.: El Colegio de México, 2007.

García Márquez, Enrique. "La privatización de Altos Hornos de México." Trabajo y Democracia, no. 104 (Julio-agosto 2009 2009): 136.

Gil, Javier. "Conversación con Javier Gil, ex militante de Política Popular." por Jorge Puma (30 de septiembre 2013).

Gordillo, Gustavo. Campesinos al asalto del cielo. Una reforma agraria con autonomía. México, D.F.: Siglo XXI, 1988.

Guevara, Roberto, y Dolores Cháirez. "Entrevista a Alberto Guevara y su esposa Lola, colonos de Tierra y Libertad, Torreón, Coahuila." (26 de agosto de 2013).

Haber, Paul Lawrance. "¡Vamos por la dignidad de Durango! Un estudio del poder sociopolítico." en Movimientos sociales e identidades colectivas. México en la década de los noventas, editado por Sergio Zermeño. México, D.F.: La Jornada Ediciones-Centro de Investigaciones Interdisciplinarias en Ciencias y Humanidades/UNAM, 1997, 55-108.

Harvey, Neil. "La lucha por la tierra en Chiapas: estrategias del movimiento campesino." en Movimientos sociales en México durante la década de los 80, editado por Sergio Zermeño y Jesús Aurelio Cuevas Díaz, México, D.F.: UNAM, 1990. , 187-202.

_-_. "La Unión de Uniones de Chiapas y los retos políticos del desarrolo de base." en Autonomía y nuevos sujetos sociales en el desarrollo rural, editado por Julio Moguel, Carlota Botey y Luis Hernández Navarro. México, D.F.: Siglo XXI-CEHAM, 1992, 219234.

Hernández Navarro, Luis. "Camilo Chávez, el metalúrgico rojo." La Jornada, 4 de enero 2011. 
Jorge Puma, Los maoístas del norte de México: breve historia de Política Popular-Línea Proletaria, 1969-1979 / Maoists of Northern Mexico: A Short History of Política Popular-Línea Proletaria, 1969-1979, Revista Izquierdas, 27, abril 2016, ISSN 0718-5049, pp. 200-229

- - - "La UNORCA: Doce tesis sobre el nuevo liderazgo campesino en México." en Autonomía y nuevos sujetos sociales en el desarrollo rural, editado por Julio Moguel, Carlota Botey y Luis Hernández Navarro, 55-77. México, D.F.: Siglo XXI editores, 1992.

Hernández Vélez, Salvador. "Entrevista con Salvador Hernández Vélez, ex militante de Línea Proletaria en Torreón." por Jorge Puma (12 de agosto 2013).

Jaquez, Antonio. "Hablan tres fundadores del movimiento Tierra y Libertad. Los apoyos de Línea de Masas: Echeverría, Moya Palencia, Manuel Camacho, Lozoya, Raúl Salinas de Gortari." Proceso, 24 de enero de 1994.

Legorreta Díaz, Ma. del Carmen. Religión, política y guerrilla en Las Cañadas de la Selva Lacandona. México, D.F.: Cal y Arena, 1998.

León López, Arturo. El movimiento campesino en los Llanos de Victoria, Durango, 1970-1980. Breviarios de la Investigación. México, D.F: UAM Xochimilco, 1986.

Línea Proletaria. "Contextos en los que fueron publicados los folletos de la organización." editado por Línea Proletaria. México, 1977.

——_. "Formas actuales de centralización." editado por Línea Proletaria. México, 1977.

- - - "Renuncia irrevocable... consenso en la Coordinadora General." editado por Línea Proletaria. México, 1979.

-——. "¿Qué es la Línea Proletaria?" en Rebelión en Chiapas. Una antología histórica. editado por John Womack Jr., México, D.F.: Random House Mondadori, 2009. 255-261.

Martínez Guzmán, Gabino. CDP. El Poder del Pueblo. Durango, México: Universidad Juárez del Estado de Durango, 2012.

Morales Bermudez, Jesús Teófilo. "Pensamiento y catolicidad en Chiapas: la diócesis de San Cristóbal de las Casas 1950-1995." Escuela Nacional de Antropología e Historia, 2004.

Morales, Luz María. "Entrevista a Luz María Morales, ex militante de Línea Proletaria y abogada de la sección 147 del sindicato minero." por Jorge Puma (30 de agosto 2013).

Orive Bellinger, Adolfo. "Conversación con Adolfo Orive." por Jorge Puma (Junio 2012).

___. "Entrevista a Adolfo Orive." por Jorge Puma (10 de agosto de 2012).

__—. "Entrevista a Adolfo Orive II." por Jorge Puma (18 de octubre 2012).

[Orive Bellinger, Adolfo]. Hacia una política popular. Libros UJED. Durango: Editorial Universidad Juárez del Estado de Durango, 2006.

Orive Bellinger, Adolfo, y José Luis Torres. Poder Popular. Construcción de ciudadanía y comunidad. México, D. F.: Juan Pablos-Fundación México Social Siglo XXI, 2010.

Ortega Olivares, Mario. Octubre Dos. Historias del movimiento estudiantil. Colección Tablado Iberoamericano. 2 ed. México, D.F.: Editorial Sierpe, 2013.

Puma Crespo, Jorge Ivan. "Populismo Maoísta: Un sendero que no condujo a la lucha armada. 1968-1979." Centro de Investigación y Docencia Económicas, 2014.

Sánchez Galindo, José Augusto. "Entrevista con Augusto "Guti" Sánchez Galindo, ex militante de Línea Proletaria en Gómez Palacio, Durango." por Jorge Puma (28 de agosto 2013).

Valdés Dávila, Carlos Manuel. "Entrevista con Carlos Manuel Valdés Dávila ex militante de Unión del Pueblo en Chiapas." por Jorge Puma (13 de agosto 2013).

Villarreal, Diana R., y Víctor Castañeda. Urbanización y autoconstrucción de vivienda en Monterrey. México, D.F.: Centro de Ecodesarrollo, 1986.

Vos, Jan de. Una tierra para sembrar sueños. Historia reciente de la Selva Lacandona 19502000. México, D.F.: Fondo de Cultura Económica, 2002. 